\section{Miguel Ángel Auladell Pérez}

Profesor titular E.U. de literatura española de la Universidad de Alicante. Su actividad docente e investigadora se ha centrado principalmente en la literatura española del siglo XVII y de la época de Fin de Siglo. Ha formado parte de varios proyectos de investigación, tanto de financiación pública como privada. Ha participado en numerosos congresos nacionales e internacionales de su especialidad y ha publicado artículos sobre diversos escritores barrocos (Liñán y Verdugo, Lope de Vega, Ruiz de Alarcón, Calderón) y finiseculares (Rubén Darío, Azorín). Es autor de la monografía titulada $L a$ 'Guía y avisos de forasteros que vienen a la Corte' del Ldo. Antonio Liñán y Verdugo en su contexto literario y editor del Ensayo bio-bibliográfico de escritores de Alicante y su provincia de Manuel Rico García. Asimismo, ha editado una Antología de poesía y prosa de Rubén Darío. Actualmente, dirige la edición digital de la obra de Lope de Vega en la Biblioteca Virtual Cervantes.

\section{1}

Junto con el fitulado "Lastarria», se trajaba de los primeros cuatro sonetos alejandrinos de su autor. El propio Rubén en El viaje a $\mathrm{Ni}$ caragua e historia de mis libros (Madrid, Mundo Latino, [1919], pág. 203) Historia de mis libros (pág. 203) afirma que el soneto «Caupolicán» «inició la entrada del soneto alejandrino a la francesa en nuestra lengua - al menos según mi conocimiento-». Es interesante apuntar el hecho de que José Victorino Lastarria (1817-1888), considerado como el padre de la novela chilena, había publicado en 1844 Investigaciones sobre la influencia social de la conquista y sistema colonial de los españoles en Chile.

2

Enrique Hernández Miyares (Santiago de Cuba, 1839-1914) fue redactor de varios periódicos y llegó a dirigir La joven Cuba en donde publicaron importantes poetas como, por ejemplo, Darío. También fue director de La Habana Elegante desde el inicio de 1888 hasta su desaparición en 1896 .

3

Carmen Ruiz Barrionuevo, "'En su loco afanar la mente mía': de

\title{
DE CAUPOLICÁN A RUBÉN DARío
}

Miguel ÁNGEL AULADELL PÉREZ

Rubén Darío publicó su conocido «Caupolicán» en el diario santiaguino La Época el 11 de noviembre de 1888. Bajo el título de «El Toqui», venía acompañado de otros dos sonetos, «Chinampa» $y$ «El sueño del Inca», agrupados con el nombre de «Sonetos Americanos»1. Si bien no apareció en la edición de Azul... publicada en Valparaíso en julio de ese mismo año, fue incluido después en la edición de Guatemala de 1890 junto con otros poemas más. Tal y como apareció en la misma, lo reproduzco a continuación:

\section{CAUPOLICÁN}

\section{á Henrique Hernández Miyares²}

Es algo formidable que vió la vieja raza:

Robusto tronco de árbol al hombro de un campeón Salvaje y aguerrido, cuya fornida maza

Blandiera el brazo de Hércules, ó el brazo de Sansón.

Por casco sus cabellos, su pecho por coraza, Pudiera tal guerrero, de Aráuco en la región, Lancero de los bosques, Nemrod que todo caza, Desjarretar un toro, ó estrangular un león.

Anduvo, anduvo, anduvo. Le vió la luz del día, Le vió la tarde pálida, le vió la noche fría, Y siempre el tronco de árbol á cuestas del titán.

« El Toqui, el Toqui!» clama la conmovida casta. Anduvo, anduvo, anduvo. La Aurora dijo: «Basta.» E irguióse la alta frente del gran Caupolicán.

Epistolas y poemas a Prosas profanas», en Alfonso García Morales (ed.), Rubén Darío. Estudios en el centenario de 'Los raros' y 'Prosas profanas', Salamanca, Secretariado de Publicaciones de la Universidad de Sevilla, 1998, pág. 26.
Se ha repetido hasta la saciedad que Rubén habría introducido nuevos textos en $A z u l .$. para tratar de paliar en lo posible la acusación de «galicismo mental» que le había propinado Juan Valera en dos de sus Cartas americanas dirigidas al nicaragüense. Esos nuevos textos caminarían por senderos estéticos no tan marcadamente parnasianos ni decadentes, dejarían a un lado lo versallesco e, incluso, acogerían algún motivo americano, tal el caso de "Caupolicán». La cuestión es que se añade un reducido número de poemas, la mayor parte sonetos, y que, excepto los «Medallones» referidos al estadounidense Walt Whitman, al cubano José Joaquín Palma y al mexicano Salvador Díaz Mirón, el resto está referido a parnasianos franceses (Leconte de Lisle y Catulle Mendès) o a motivos típicos del Parnaso como, por ejemplo, las diversas ambientaciones exóticas que presentan «Venus» $y$ «De invierno». Todo ello, sin olvidar el poema titulado «A un poeta», de marcada ascendencia romántica, que vaticina uno de los temas más tratados por Rubén, el del poeta y la poesía. Según Carmen Ruiz Barrionuevo, se trataría de un «loco afanar» que describe bastante bien lo que constituyó la reflexión poética de Dario desde su época juvenil. Subraya la catedrática de Salamanca que, frente a los que sostienen la tesis del collage resultante al aparecer la segunda edición de Azul..., Rubén Darío habría llevado a cabo un incremento estéticamente intencionado: «Más bien, parece que superando el origen disperso de la publicación de muchos de sus títulos en periódicos, resulta un libro cuidadosamente engarzado, en el filo de un abismo que entonces hubo de ser difícil de captar, porque la unidad venía ofrecida por los procedimientos, y éstos eran de una extrema novedad» ${ }^{3}$. 
Por otra parte, de la primera edición de Azul... (1888) a la segunda (1890), la sensibilidad de Rubén Darío le hace reparar en la historia del país que le acoge en ese momento. La etapa chilena del autor está protagonizada por su relación con su apreciado Gilbert, pseudónimo de Pedro Balmaceda Toro, hijo del entonces Presidente de la República, al que el poeta dedicó su Canto épico a las glorias de Chile. Al igual que ocurre con Buenos Aires -una de las siguientes etapas biográficas-, el caso de Santiago de Chile es en aquel momento el de esas ciudades emergentes que ven constituirse una pequeña burguesía que va protagonizando la vida urbana, que asiste a un relativo progreso económico y que le acerca más a la cotidianeidad de algunas urbes europeas que a los inmensos territorios que les circundan. También en cuanto a las corrientes estéticas es determinante ese paulatino cambio social. El caso de la residencia del mandatario chileno es un síntoma extraordinario, puesto que el joven Balmaceda dispone allí de una biblioteca donde Darío irá conociendo la tradición de la poesía francesa, antes de viajar a $\mathrm{Pa}$ rís, a la vez que se empapa de los intríngulis de la historia y la política chilenas.

El soneto «Caupolicán» se nos presenta como un texto paradigmático del intento de alejamiento de lo afrancesado, tal vez incitado por las cartas de Valera, y, a la vez, como antesala de otros ejemplos de reivindicación indígena de más fama todavía, como la «Salutación del optimista» o la oda «A Roosevelt», incluidos en Cantos de vida y esperanza en 1905. No obstante, pueden advertirse en «Caupolicán» otros componentes característicos del modernismo que -parafraseando a Gil de Biedma ${ }^{4}$ - guardan relación con la restauración de la tradición olvidada, y que por lo mismo son también prueba de la práctica culturalista de los escritores finiseculares. Es altamente significativo el hecho de que en la edición de Guatemala, en la cual se incluye el poema, Rubén decida suprimir la extensa dedicatoria a Federico Varela que encabezaba la edición de Valparaíso y que mostraba una notable pasión culturalista. Ahora conserva el prólogo del académico correspondiente de la Española Eduardo de la Barra e indica en la portada que se trata de la segunda edición aumentada precedida de un estudio sobre la obra por Don Juan Valera de la Real Academia Española. Podemos preguntarnos si el rubor del

poeta impidió la inclusión de aquella dedicatoria de la «enredadera de campánulas», y ello teniendo presente que aún faltaría bastante tiempo, hasta llegar el año 1899, para que José Enrique Rodó dedicara un artículo a su figura que albergaría la famosa especie que sacada de su contexto hizo tanta fortuna enseguida: «Rubén Darío no es el poeta de América».

Prueba, sin embargo, del ingrediente americano que Rubén Darío acoge a lo largo de toda su producción es precisamente el soneto titulado primero «El Toqui» y más tarde «Caupolicán», en que se sintetiza uno de los más conocidos episodios protagonizados por ese guerrero araucano y que al tiempo constituye una pieza de orfebrería en la rica tradición literaria anterior y posterior que dicho motivo ha propiciado. Mario Benedetti en un artículo titulado «Rubén Darío, Señor de los tristes» publicado en 1967, habla de sus «poemas concentrados, notales, indiscutibles obras maestras» ${ }^{5}$. El poema «Caupolicán» puede considerarse así, en el sentido de que supone un ejercicio extraordinario de condensación y de aprovechamiento intertextual. El propio Eduardo de la Barra, autor del alambicado prólogo de $A z u l . .$. dice literalmente: «Su originalidad incontestable está en que todo lo amalgama, lo funde y lo armoniza en un estilo suyo, nervioso, [...] y de palabras bizarras, exóticas aún, mas siempre bien sonantes» (epígrafe IV). Alude el tema del poema a la prueba que enfrentó a varios caciques araucanos consistente en sostener durante tres jornadas un pesado tronco de árbol para dilucidar según la fuerza empleada, la habilidad demostrada y la capacidad de resistencia, quién acaudillaría a su pueblo frente a los invasores españoles abanderados por el hijo del Virrey del Perú, don García Hurtado de Mendoza.

La historia de Caupolicán nos ha llegado a partir de una relativamente extensa tradición textual detallada por el gran polígrafo José Toribio Medina ${ }^{6}$ y que tiene su comienzo en $L a$

4

Cfr. Jaime Gil de Biedma, "Función de la poesía y fun- ción de la crítica», por T.S. Eliot", El pie de la letra, Barcelona, Crítica, 1994, pág. 18.

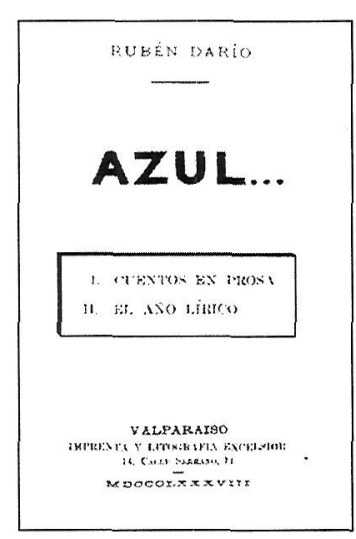

Azul (Valparaíso, 1888).

5

Mario Benedetti, El ejercicio del criterio, Madrid, Alfaguara, 1995, apud Carmen Alemany Bay, «El cuestionamiento del modernismo en la poesía coloquial», en Trinidad Barrera (ed.), Modernismo y modernidad en el ámbito hispánico, Sevilla, Universidad Internacional de Andalucía. Sede lberoamericana de la Rábida/Asociación Española de Estudios Literarios Hispanoamericanos, 1998, pág. 345.

6

Vid. José Carlos Rovira, José Toribio Medina y su fundación literaria y bibliográfica del mundo colonial americano, Santiago de Chile, DIBAM/Centro de Investigaciones Diego Barros Arana, 2002.

De Caupolicán a Rubén Darío MIGUEL Á. AULADELL PÉREZ 


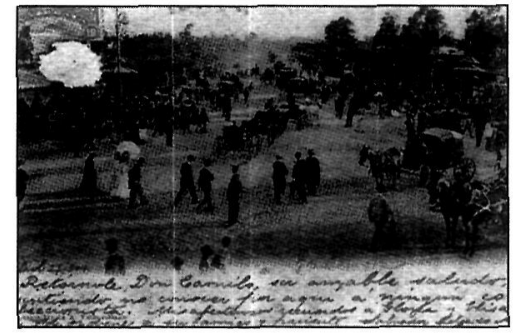

Guatemala 1890.

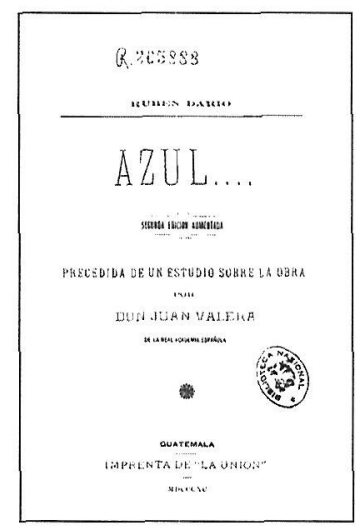

Azul (Guatemala, 1890).

\section{7}

Patricio Lerzundi, Arauco en el teatro del Siglo de Oro, Valencia, Albatros Hispanófila, 1996, pág. 10.

8

Claudio Cifuentes Aldunate, "Caupolicán: creación y recreaciones de un mito», Noter og kommentarer fra Romansk Institut, Odense Universiter, 1982, núm. 53, pág. 64

9

Sobre los bautizos de caciques puede verse Tzvetan Todorov, La Conquista de América. El problema del otro, México, Siglo $\mathrm{XXI}, 2001^{12}\left(1^{9}\right.$ ed. en francés: 1982), pág. 183.

De Caupolicán a Rubén Darío MIGUEL Á. AULADELL PÉREZ
Araucana de Alonso de Ercilla. De todas maneras, es de notar la existencia de otro tipo de documentos que también aluden al episodio antedicho y que, en general, dan cuenta, más o menos fidedignamente, de los hechos históricos que acontecieron en los primeros lustros de la conquista del territorio que actualmente ocupa Chile.

El episodio en cuestión se incardina en la sucesión de acontecimientos ocurridos hacia mediados del siglo XVI en plena expansión de las fundaciones españolas que dependientes del virreinato del Perú se llevaban a cabo por la región andina y que contó con enormes dificultades de sometimiento al llegar a la zona del río Bío Bío. Vivían tras esa verdadera línea fronteriza unos pueblos caracterizados por su gran fiereza. Fueron concretamente los mapuches los que atacaron inmediatamente a los invasores europeos y destruyeron la ciudad de Santiago, dando comienzo a las llamadas como guerras de Arauco. Afirma Patricio Lerzundi que:

Los araucanos -que fue el nombre que les dieron los españoles a los mapuches por cuanto vivían en la región de Arauco-, eran los más belicosos de los grupos indígenas. Su lengua era el mapuche; desconocian, sin embargo, la escritura y no dejaron constancia por lo tanto de su historia y expresiones artísticas. Tampoco dejaron monumentos y su cultura distaba mucho de la alcanzada por sus vecinos incas. Se sabe que adoraban a Apó como el ser supremo y temían a Pillán, el demonio. El concepto de Dios era similar a la cristiana [sic], en el sentido de que lo consideraban un creador y pastor de la Tierra, donde la humanidad era un rebaño. Vestían rústicamente, sin grandes adornos; vivían en rucas, que eran habitaciones construidas principalmente de paja. Existía la poligamia, generalmente se reunían para tratar asuntos especiales, como la guerra, bajo el control del toqui, o jefe supremo, que era elegido por una asamblea de grupos de familia, o cahuines?.

Ese pueblo es el que infligiría enormes bajas a las fuerzas de conquista y acabaría con grandes símbolos de los invasores. La tremenda rivalidad de que hicieron gala los contendientes aseguró una pléyade de testimonios literarios que por uno $\mathrm{u}$ otro motivo quisieron hacerse eco de aquel acontecer histórico. Nombres como Lautaro, Caupolicán, Galba- rino, Colo Colo, -por los mapuches-; y como Pedro de Valdivia, Francisco de Villagra, García Hurtado de Mendoza o el mismo Alonso de Ercilla -por los españoles-, configuran un elenco de personajes que van a ser leídos y reconocidos en el sentido categórico que atribuye Roland Barthes a ese tipo de tradición literaria que en cada reescritura va transformando el motivo, el tema, el mito. En resumen, un conjunto de dramatis personae que son uña y carne de la re-creación a lo largo del tiempo y que, sobre todo, tuvo durante el siglo XVII su mejor traslación precisamente al género teatral. También algunos lugares van a conformar la geografía de toda esa estela intertextual: Santiago, La Serena, Tucapel, Pilmaiquén, Cañete. Por consiguiente, es preciso resaltar una vez más cómo la creación artística, en esta ocasión la literatura, contribuye a edificar culturalmente un nuevo mundo, pero simultáneamente éste abastece de extraordinarios e insólitos recursos al canon retórico del humanismo y posteriormente de otras estéticas que van emergiendo en Europa.

Al erigirse La Araucana de Ercilla como primera piedra, podemos apreciar hasta qué punto el grandioso poema marca todas las posibilidades de recreación del motivo que nos ocupa. Claudio Cifuentes Aldunate en un ilustrativo artículo de enfoque semiótico llega a fijar en cinco las etapas de evolución del personaje de Caupolicán y sus correspondientes representaciones:

1. Unidad dual. Fuerza corporal e inteligencia al servicio de su pueblo. Vencedor, famoso y en equidad de roles con Carlos V.

2. Desintegración de su imagen. Unidad dual de fuerza e inteligencia al servicio de sí mismo. Pérdidas bélicas, pérdida de prestigio y de fama.

3. Restablecimiento parcial de su imagen a través de la elocuencia y sagacidad.

4. Desintegración total de su imagen en la persecución y apresamiento.

5. Recuperación de su integridad a través del bautizo9 y la muerte. Valiente, temido y digno, es ejecutado con el atributo cristiano del que carecía.

Puede afirmarse que toda re-escritura de la historia de Caupolicán recoge una, dos o más de estas etapas. Eso sí, en algunos casos se incluyen motivos nuevos que van enrique- 
ciendo el tema; en otros son el tono o el recipiente genérico los que aportan una peculiaridad sobresaliente y genuina a determinada obra. Hay también procesos curiosos como la posible influencia de algunos motivos en obras teatrales barrocas que, en principio, van a representarse en el ámbito peninsular. $\mathrm{Me}$ refiero, por ejemplo, a la presencia del componente canibalesco existente en las prácticas rituales de muchos pueblos indígenas ${ }^{10}$ y que llegan a aparecer como recurso dramático en obras como Morir pensando matar de Francisco de Rojas Zorrilla, en la que la protagonista Rosimunda va a brindar en escena con el cráneo de su difunto padre, el rey, siguiendo la indicación de Alboino, su esposo, que trata de convencerla a propósito de tal costumbre de los longobardos como tributo a los vencidos. Nos preguntamos por qué Rojas Zorrilla escoge un elemento tan escabroso que remite a tiempos de las invasiones bárbaras y no podemos dejar de pensar en la relativa facilidad para introducir esas prácticas en el ámbito de la convención teatral, movidos por la cercanía de noticias relacionadas con ese asunto provenientes de América; es más, veamos como hay alusión explícita a territorios transatlánticos:

ROSIMUNDA. No dejéis por mí las mesas.

Seguid el convite torpe, que más de caribes fieros parece que no de hombres ¿De qué feroz troglodita, de aquellos que hambrientos comen humana carne, de aquellos que sangre racional sorben, se escribe que cometiese un delito tan enorme, una crueldad tan injusta, entre mil culpas atroces?!1

Para indagar en la síntesis que Darío lleva a cabo de una de esas etapas de desarrollo del personaje plasmado por Ercilla concretamente en el canto II de la primera parte de La Araucana (1569), he desempolvado un viejo articulito de Homero Castillo ${ }^{12}$ que no aparece citado en la bibliografía al uso sobre nuestro tema. Me corrobora la hipótesis de trabajo que defiendo aquí, aunque a riesgo de ser poco precavido, deseo subrayar que las ramificaciones que advierte el veterano crítico con respecto a esos dos textos no son más que un constitu- yente de toda una intrincada red que recorre la práctica totalidad de las obras que tratan el asunto, afecta a manifestaciones genéricas diversas y todo ello a través del tiempo, al menos desde la publicación de la epopeya chilena.

Sin aspirar a ser exhaustivos, relacionaremos a continuación los textos que antes del famoso soneto de Darío contribuyeron a hacer crecer el árbol literario que ha ido enramándose con el formidable y proteico personaje de Caupolicán. Es curioso observar que prácticamente todos los géneros literarios han cultivado el motivo de nuestro interés y también es destacable el hecho de que la importancia intrínseca del personaje y del hombre han motivado la atención al mismo en la correspondencia de sus rivales, los conquistadores españoles, y así tenemos como uno de los primeros testimonios relativos al formidable guerrero las cartas de Pedro de Valdivia. Enseguida, han de señalarse las crónicas que aparte de su carácter documental encierran en muchos de los casos valiosos ejercicios estilísticos que adquieren una categoría literaria. Se trata de: Crónica y relación copiosa y verdadera de los reinos de Chile, de Gerónimo de Bibar; Historia de Chile desde su descubrimiento hasta el año 1575, de Alonso de Góngora Marmolejo; Crónica del reino de Chile, de Pedro Mariño de Lobera y Bartolomé de Escobar; Hechos de don García Hurtado de Mendoza, cuarto marqués de Cañete, de Cristóbal Suárez de Figueroa. Entre los textos de carácter literario destacan dos obras: la ya mencionada de Alonso de Ercilla -La Araucana-, y Arauco domado (1596), de Pedro de Oña; estas obras siguen el patrón del género épico en práctica durante el Renacimiento y están directamente relacionadas por cuanto la segunda es pieza de encargo para tratar de corregir algunos de los extremos que, según algunos, contenía el poema de Ercilla y también por razón de que Arauco domado comienza su andadura a partir de un momento recogido en la primera de las tres partes de La Araucana. Ya en el siglo XVII, el tema de Caupolicán y todos los motivos que lleva anejos se constituye como elección predilecta para el género dramático. Y así tenemos: Arauco domado (Parte $X X, 1625)$ de Lope de Vega; El gobernador prudente (1663), de Gaspar de Ávila; La belligera española (1616) de Ricardo del Turia; Algunas hazañas de las muchas de don García Hurtado de Mendoza, Marqués de Cañete

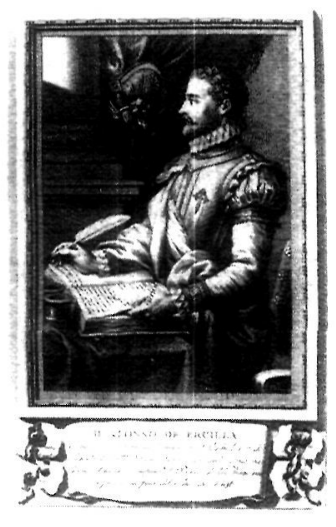

Ercilla (grabado).

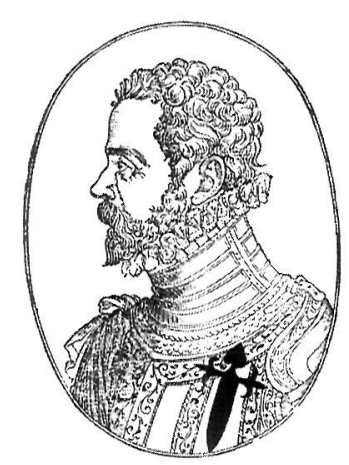

Retrato de Alfonso de Ercilla. Grabado que aparece en La Araucana. Salamanca 1570.

10

Ibidem, págs. 159 y ss.

11

Francisco de Rojas Zorrilla, Morir pensando matar / La vida en el ataúd, ed. Raymond R. MacCurdy, Madrid, Espasa-Calpe, 1976, pág. 29.

12

Homero Castillo, "Caupolicán, en el modernismo de Darío", Revista Iberoamericana (Millwood, N.Y.), oct.-1953/sept.-1954, t. XIX, núms. 37-38, págs. 111 118 .

De Caupolicán a Rubén Darío MIGUEL Á. AULADELL PÉREZ 


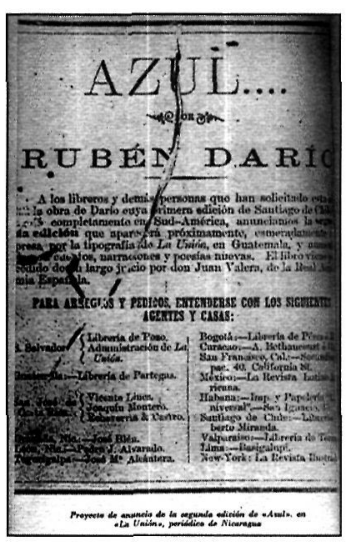

Publicidad $2^{\mathrm{a}}$ ed. Azul.

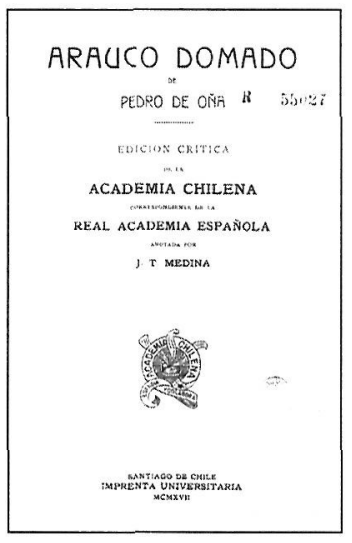

Arauco Domado, de Pedro de Oña.

13

Max Henríquez Ureña, Breve historia del modernismo, México, FCE, 1978, pág. 335
(1622) de Luis de Belmonte Bermúdez y colaboradores; Los españoles en Chile (1665) de Francisco González de Bustos; y el auto sacramental La Araucana (principios del s. XVII), también de Lope de Vega.

Otros textos literarios inspirados directa o indirectamente por el tema de Arauco son los siguientes: Quince romances anónimos basados en La Araucana (1589-1593); Cuarta y Quinta parte de La Araucana, poema épico de Diego de Santisteban de Osorio (1598); Historia Tragicómica de don Enrique de Castro, novela de caballerías de Francisco de Loubayssin de la Marca (París, 1617); Las guerras de Chile, poema épico de Juan de Mendoza Monteagudo, editado por José Toribio Medina en 1888; Purén indómito, crónica rimada de Hernando Álvarez de Toledo; El cautiverio feliz, memorias en verso de Francisco Núñez de Pineda y Bascuñán, publicadas en 1863; Restauración de la Imperial y conversión de almas infieles, novela de Fray Juan de Barrenechea y Alvis (ca. 1693).

Tras el paréntesis ilustrado y romántico, el gusto por la mitología de la estética modernista posibilita que nuestro tema vuelva a reescribirse. $\mathrm{Y}$ he aquí otra muestra recreadora del mito distinta de la de Darío: el «Caupolicán» de José Santos Chocano, primero de los sonetos incluidos en el «Tríptico heroico» de Alma América (1906):

\section{CAUPOLICÁN}

Ya todos los caciques probaron el madero.

- ¿Quién falta? - Y la respuesta fue un arrogante: - ¡Yo! - ¡Yo! -dijo; y, en la forma de una visión de Homero, del fondo de los bosques Caupolicán surgió.

Echóse el tronco encima, con ademán ligero; y estremecerse pudo, pero doblarse no.

Bajo sus pies, tres días crujir hizo el sendero; y estuvo andando... andando... y andando se durmió.

Andando, así, dormido, vio en sueños al verdugo: él muerto sobre un tronco, su raza con el yugo, inútil todo esfuerzo y el mundo siempre igual.

Por eso, al tercer día de andar por valle y sierra, el tronco alzó en los aires y lo clavó en la tierra ¡como si el tronco fuese su mismo pedestal!

El traer aquí este poema de José Santos Chocano está directamente relacionado con la característica simpatía hacia el indio (peruano, mexicano, centroamericano) que el autor mostró, ya en su madurez, en Tres notas de nuestra alma indígena, en forma que, según Max Henríquez Ureña ${ }^{13}$, no habría desdeñado González Prada:
Indio que labras con fatiga
tierras que de otros dueños son,
¿ignoras tú que deben tuyas
ser, por tu sangre y tu sudor?
¿ignoras tú que audaz codicia,
siglos atrás, te las quitó?,
¿ignoras tú que eres el Amo?
- ¡Quién sabe, señor!

Chocano que era descendiente por línea directa del Gran Capitán, fue militante indigenista hasta el punto de criticar acremente Los Raros de Darío por no ser «americanos». Ese carácter le aleja del tono que posee el soneto del nicaragüense.

Además de todo lo relacionado, debemos aludir también a la importante presencia del tema en otros ámbitos artísticos como la plástica o la música. Asimismo, es imposible dejar de mencionar alguna muestra posterior a Darío como mejor modo de corroborar el éxito del motivo y la atención que le han dispensado creadores tan diversos. El caso más excelso es, sin duda, el de Pablo Neruda. Entre sus muchos escritos de preocupación directa por el mundo indígena, destacan dos poemas - «Toqui Caupolicán» (V) y «El empalado» (VII)- pertenecientes a la serie titulada «Los Libertadores», incluida en el Canto general (1950):

\section{TOQUI CAUPOLICÁN}

En la cepa secreta del raulí creció Caupolicán, torso y tormenta, y cuando hacia las armas invasoras su pueblo dirigió, anduvo el árbol, anduvo el árbol duro de la patria. Los invasores vieron el follaje moverse en medio de la bruma verde, las gruesas ramas y la vestidura de innumerables hojas y amenazas, el tronco terrenal hacerse pueblo, las raíces salir del territorio.

Supieron que la hora

al reloj de la vida y de la muerte. 
Otros árboles con él vinieron.

Toda la raza de ramajes rojos, todas las trenzas del dolor silvestre, todo el nudo del odio en la madera. Caupolicán, su máscara de lianas levanta frente al invasor perdido: no es la pintada pluma emperadora, no es el resplandeciente collar del sacerdote, no es el guante ni el príncipe dorado:

es un rostro del bosque, un mascarón de acacias arrasadas, una figura rota por la lluvia, una cabeza con enredaderas.

De Caupolicán el Toqui es la mirada hundida, de universo montañoso, los ojos implacables de la tierra, y las mejillas del titán son muros escalados por rayos y raíces.

\section{EL EMPALADO}

Pero Caupolicán llegó al tormento.

Ensartado en la lanza del suplicio, entró en la muerte lenta de los árboles.

Arauco replegó su ataque verde, sintió en las sombras el escalofrío, clavó en la tierra la cabeza, se agazapó con sus dolores.

El Toqui dormía en la muerte. Un ruido de hierro llegaba del campamento, una corona de carcajadas extranjeras, y hacia los bosques enlutados sólo la noche palpitaba.

No era el dolor, la mordedura del volcán abierto en las vísceras, era sólo un sueño del bosque, el árbol que se desangraba.

En las entrañas de mi patria entraba la punta asesina hiriendo las tierras sagradas. La sangre quemante caía de silencio en silencio, abajo, hacia donde está la semilla esperando la primavera.

Más hondo caía esta sangre.
Hacia las raíces caía.

Hacia los muertos caía.

Hacia los que iban a nacer.

En el momento actual, todavía Caupolicán sigue re-escribiéndose. Cuando el problema mapuche está aún lejos de quedar resuelto, pueden visitarse a través de internet varios lugares en donde el guerrero sigue irguiendo su «alta frente» porque siguen escribiéndose poemas que tienen como referente ese imaginario cultural que en la época de Fin de Siglo contribuyó a universalizar el poeta de Nicaragua y de América. En aquellos territorios geográficos y sociales donde aún no se ha llegado a completar el proceso de destrucción de la «sagrada selva», asistimos casi con perplejidad a empresas como las que propició Rubén y que José Carlos Rovira tan acertadamente ha reflejado al reparar en la «desbordante actividad en poesía»-al menos hasta la última década del siglo XX- de un país tan poco extenso y poblado como Nicaragua; se trata de un fenómeno -dice- que tiene que ver «quizá también con un imaginario cultural que, desde comienzos de siglo, hizo de la figura del poeta un símbolo de prestigio y un factor de definitiva universalidad [...] La figura era Rubén Darío y cada nicaragüense debe pensar en lo que significó Darío para universalizar una literatura, globalmente la hispanoamericana; en concreto, la propia. La figura del poeta tiene así una elevada imagen que significa lo universal ante la propia sociedad $»^{14}$.

Desde luego, esa «elevada imagen» del poeta pensamos que está implícita hasta desde un punto de vista puramente estético en el comentado soneto de "Caupolicán» de Rubén Darío. Eduardo de la Barra en el «Prólogo» a Azul... se interroga al respecto: «¿Veis? -El protagonista es el Poeta, siempre el Poeta, solo, desconocido, [...], y, sin embargo, como Colón lleva un mundo a la cabeza» (epígrafe IX) Siguiendo el canon retórico tan recurrente en todas las expresiones de la lírica modernista, esta composición podría leerse también en clave metapoética, en el sentido de apreciarse como la exclamación del poeta nicaragüense que ha de ser de formidable naturaleza para presentarse ante el mundo, para ser recibido como tal poeta. Esa reflexión acerca

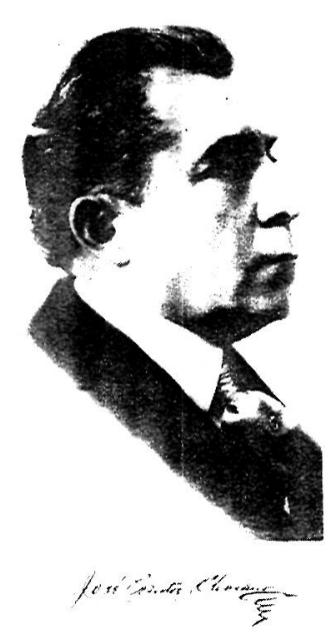

José Santos Chocano.

14

José Carlos Rovira, «Nicaragua: La destrucción de 'La sagrada selva'», en W.AA., La poesía nueva en el mundo hispánico, Madrid, Visor, 1994, pág. 217. Cfr. también J.C. Rovira, «Espacios simbólicos y urbanos en Darío: desde 'La sagrada selva' a 'La gran cosmópolis'», Anthropos, enero-abril 1997, núms. 170171, págs. 76-80.

De Caupolicán a Rubén Darío MIGUEL Á. AULADELL PÉREZ 
Vid. Federico García Lorca, Poeta en Nueva York, ed. Piero Menarini, Madrid, Espasa-Calpe, 1998, págs. 29-30

\section{6}

Se trata del primer poema de los que se añadieron en la segunda edición de Guatemala (1890). De todas formas, en dicha edición, aparecen separados por el poema titulado «Ananke». Fue en la tercera edición, de 1905 (Buenos Aires, Biblioteca de 'La Nación'), cuando "A un poeta» -aunque datado en mayo de 1890 , en que apareció publicado en La Unión de San Salvadorprecedió inmediatamente al soneto.

17

Teodosio Fernández, "Sobre Rubén Darío y el regeneracionismo modernista", CHA, febr. 1992, núm. 500, pág. 208.

18

Vid. los trabajos de Cristina Naupert: La tematología comparatista entre teoría y práctica, Madrid, Arco/Libros, 2001; y Tematología y comparatismo literario, introd., compilación y biografía de..., Madrid, Arco/Libros, 2003.

19

"Compañero Alonso de Ercilla: La Araucana no es sólo un poema: es un camino». Cit. por Juan María Corominas, Castiglione y La Araucana. Estudio de una Influencia, Madrid, José Porrúa Turanzas (Studia Humanitatis), 1980, portada.

De Caupolicán a Rubén Dario MIGUEL Á. AULADELL PÉREZ de la dificultad de ser entendido como poeta y de la fortaleza necesaria para seguir alimentando la llama de la poesía nos remite a otro ser dotado de especial sensibilidad como Federico García Lorca, que en su Poeta en Nueva York -libro en el que, por cierto, también encontramos el dilema naturaleza/artificio urbano-, presenta a ese poeta sin artículo frente a la gran ciudad ${ }^{15}$, encarado al mundo moderno, y lo hace planteando la dificultad que entraña ser poeta en la «gran cosmópolis»; parece que proponiendo la existencia de todo un Caupolicán, cuya fortaleza física y también espiritual (incontaminada) permita asumir los continuos nuevos retos.

La composición que suele preceder a «Caupolicán» en las ediciones de $A z u l . .$. es significativamente la titulada $\ll A$ un poeta» ${ }^{16}$. $Y$ si nos detenemos un instante en su lectura, observamos cuántos puntos de encuentro existen entre la misma y el soneto. Haciendo repaso, tenemos un léxico lleno de concomitancias con el usado en «Caupolicán»: titán, hombre-montaña, víctima, fatal martirio, Hércules loco, selva virgen, Sansón, cabellos. Asimismo, leemos expresiones como: «iQuién desquijara los robustos leones...»; «que escriba versos que parezcan lanzas», «con su casco de oro», «embiste el toro», "esclavo de unos ojos bellos». La relación que puede establecerse entre los dos textos abona una vez más la concepción de conjunto que Rubén tenía del corpus poemático de Azul..., y también subraya la idea del paralelo que puede establecerse entre Caupolicán/poeta Rubén. Nuestro autor es el guerrero que asiste al final de un mundo y se rebela contra la opresión burguesa como auténtico modernista que hace gala de su inconformismo.

Teodosio Fernández afirmaba en 1992 que: «Con su obra Darío se enfrentaba a esa incomprensión determinada por la ignorancia y el desdén. Hoy nadie duda de su formidable contribución al nacimiento de la poesía hispánica moderna. Sus aportaciones a la invención de una identidad cultural española e hispanoamericana esperan aún una valoración precisa» ${ }^{17}$.

Textos como el soneto «Caupolicán» contribuyen, sin duda, a que podamos emprender esa «valoración precisa». Sin apearse de su ideario estético, Rubén Darío configura en dicho texto una miniatura modernista que en apretada, al tiempo que rítmica, actitud sincrética, nos da cuenta de las recuperaciones de las culturas precolombinas a través de los ejercicios literarios de diversos autores americanos y españoles.

Hasta aquí esta aproximación a un asunto que merece el tratamiento pormenorizado de cada uno de los textos alegados y que es susceptible de ser abordado con un novedoso enfoque, como es la tematología ${ }^{18}$, variante crítica con la que están experimentando, sobre todo, los especialistas en literatura comparada y que creo puede resultar rentable para andar ese camino que Neruda ${ }^{19}$ decía que emprendió La Araucana de Ercilla, refiriéndose a su carácter fundacional para la recreación de motivos, tópicos, temas y mitos como, por ejemplo, el que nos ha ocupado en estas páginas, ese Caupolicán que llegó a resumirse en la expresión anafórica «anduvo, anduvo, anduvo».

\section{BIBLIOGRAFÍA}

Relaciono las fuentes primarias en donde se desarrolla de alguna manera el tema Caupolicán y las fuentes secundarias más directamente relacionadas con el mismo, aunque hayan sido citadas en las notas:

\section{Fuentes primarias}

Crónicas del reino de Chile.- Crónicas de Pedro Valdivia - Góngora Marmolejo - Pedro Mariño Lobera, ed. y estudio de Francisco Esteve Barba, Madrid, Atlas (BAE, $\left.\mathrm{n}^{\circ} 131\right), 1960, \mathrm{XXXIX}+596$ págs.

Chocano, José Santos, «Caupolicán» [incluido en el «Tríptico heroico» de Alma América], en Obras Completas, ed. Luis Alberto Sánchez, México, Aguilar, 1954, pág. 400.

Darío, Rubén, «Caupolicán», Azul..., precedida de un estudio sobre la obra por D. Juan Valera, Guatemala, Imp. «la Unión», 1890, $2^{a}$ ed. aumentada, XXXIV, 237 págs. [Primera publicación en La Época (Santiago), 11 de noviembre de 1888 , con el título «El Toqui»].

- «A un poeta», Azul..., Guatemala, 18902. [Primera publicación en La Unión (San Salvador), mayo de 1890].

- «Salutación del optimista», Cantos de vida y esperanza. Los cisnes y otros poemas, $\mathrm{Ma-}$ drid, Tip. de la 'Revista de Archivos, Bibliotecas y Museos', 1905. [Aparece por 
primera vez en la Revista Hispano-Americana (Madrid), abril 1905].

- «A Roosevelt», Cantos de vida y esperan$z a$, ed. cit. [Aparece por primera vez en Helios (Madrid), febrero 1904, y fechado en «Málaga, 1904»].

Ercilla, Alonso de, La Araucana, ed. Marcos A. Morínigo e Isaías Lerner, Madrid, Castalia, 1979.

- La Araucana, ed. Isaías Lerner, Madrid, Cátedra, 2002.

Escritores de Chile. Época colonial (Valdivia, Góngora y Marmolejo, Ercilla, Oña, Ovalle, Rosales, Tesillo, etc.), prólogo de E. Solar Correa, Santiago de Chile, Impr. Universitaria, 1932.

Góngora Marmolejo, Alonso de, Historia de Chile: desde su descubrimiento hasta el año 1575, Selección, prólogo y notas de Nelson Osorio, Santiago de Chile, Edit. Universitaria, [1969 ó 1970].

González de Bustos, Francisco de, Comedia famosa, Los Españoles en Chile (Valencia, Impr. De la Viuda de Joseph de Orga, 1761), Biblioteca Hispano-chilena, vol. II, núm. 443 , págs. 531-565.

Neruda, Pablo, «Toqui Caupolicán» y «El Empalado», en Canto general, ed. Enrico Mario Santi, Madrid, Cátedra, 1992, págs. 195-196 y 197-198.

Oña, Pedro de, Arauco domado [Lima, 1596], ed. crítica de la Academia Chilena correspondiente de la RAE anotada por J.T. Medina, Santiago de Chile, Impr. Universitaria, 1917. [Edición facsímil de la ed. de Lima (Antonio Ricardo de Turín, 1596), Madrid, Cultura Hispánica (Gráfs. Ultra), 1944].

Schodlowsky, León, «Caupolicán: relato épico: para recitante (barítono), coro mixto, 2 pianos y percusión. Música de...; texto de Pablo Neruda, 1958.

Vega, Lope de, Arauco domado por el Excelentísimo Señor Don García Hurtado de Mendoza, Bimicesa (http://cervantesvirtual.com).

\section{Fuentes secundarias}

Aguilera G., Francisco, «Historia de todas las cosas que han acaecido en el reino de Chile y de los que lo han gobernado (15361575) de Alonso de Góngora Marmolejo», Revista Chilena de Literatura (Santiago de Chile), 1990, núm. 36, págs. 105-112.
Antonucci, Fausta, «El elemento cómico en las comedias de Lope de Vega sobre la conquista española de nuevos mundos», Studia Aurea. Actas del III Congreso de la AISO, vol. II, Toulouse-Pamplona, 1996, págs. 33-39.

Becerra, Eduardo, «Chile, en la tierra del 'rey burgués' (1886-1889)», en Rubén Darío, Madrid, Eneida (Col. Semblanzas, $\mathrm{n}^{\circ}$ ), 2000, págs. 19-24.

Bellini, Giuseppe, «Lope y Tirso: dos momentos de la presencia de América en el teatro español del Siglo de Oro", en Daniel Meyrán, Alejandro Ortiz y Francis Sureda (eds.), Théâtre, Public, Societé (Teatro, Público, Sociedad) (Actes du III Colloque International sur le théâtre hispanique, hispano-américain et mexicain en France, 10, 11 et 12 octobre 1996, Université de Perpignan), Perpignan, Presses universitaires de Perpignan (Collection Études), 1998, págs. 31-42.

Blancpain, Jean-Pierre, Les Araucans et la frontière dans l'bistoire $d u$ Chili des origines au XIX' siècle. Une épopée américaine, Frankfurt am Main, Vervuert Verlag, 1990.

Castells, Isabel, «Suele Amor trocar con Marte las armas: la conquista erótica y militar del Nuevo Mundo en tres comedias de Lope», Anuario de Lope de Vega (Lleida), 1998, IV, págs. 87-96.

Cifuentes Aldunate, Claudio, «Caupolicán: creación y recreaciones de un mito", Noter of Kommentarer fra Romansk Institut (Odense Universitet, Dinamarca), 1982, núm. 53, págs. 59-77.

- «Para una semiótica de la crónica», Investigaciones semióticas IV. Actas del IV Simposio Internacional de la Asociación Española de Semiótica -Sevilla, 3-5 diciembre de 1990-(Describir, inventar, transcribir el mundo), Madrid, Visor, 1992, págs. 991997.

Corominas, Juan $\mathrm{M}^{\mathrm{a}}$., Castiglione y La Araucana, Madrid, José Porrúa Turanzas (Studia Humanitatis), 1980, pág. 47.

- «Las fuentes literarias del Arauco domado, de Lope de Vega", en Lope de Vega y los orígenes del teatro español, Madrid, 1981, págs. 161-170.

Dennis, Harry J., «'Caupolicán’ de Rubén Darío», en: [Francisco E.] Porrata y [Jorge A.] Santana, Antología comentada del modernismo. Explicación de textos litera-
De Caupolicán a Rubén Darío MIGUEL Á. AULADELL PEREZ 
rios, Introducción de Antonio Sánchez Romeralo, Medellín (Colombia), Editorial Bedout/Department of Spanish and Portuguese (California State University), 1974, págs. 236-239.

Dille, Glen F., «America tamed: Lope's Arauco domado", New Historicism and the Comedia: Poetics, Politics and Praxis, ed. J.A. Madrigal, Boulder, Co., Society of Spanish and Spanish-American Studies, 1997, págs. 111-128.

Durand, José, «Caupolicán, clave historial y épica de La Araucana", Revue de Littérature Comparée, 1978, 205-208, págs. 367-389.

Fernández, Teodosio, "La etapa chilena», en Rubén Dario, Madrid, Historia 16/ Quórum/Quinto Centenario, 1987, págs. 2337.

- «Sobre Rubén Darío y el regeneracionismo modernista», CHA, febrero 1992, núm. 500, págs. 201-208.

Invernizzi Santa Cruz, Lucía, «Los trabajos de la guerra y Los trabajos del hambre: Dos ejes del discurso narrativo de la conquista de Chile (Valdivia, Vivar, Góngora Marmolejo)», Revista Chilena de Literatura (Santiago de Chile), 1990, núm. 36, págs. 7-15.

Kirschner, Teresa J., «Encounter and Assimilation of the Other in Arauco domado and La Araucana by Lope de Vega», en John C. Hawley (ed.), Christian Encounters with the Other, preface Erick D. Lange, New York, New York University Press, 1998, págs. 33-43.

- «La evocación de las Indias en el teatro de Lope de Vega: una estrategia de inclusión», en Agustín de la Granja y Juan Antonio Martínez Berbel (eds.), Mira de Amescua en candelero. Actas del Congreso Internacional sobre Mira de Amescua y el teatro español del siglo XVII (Granada, 27-30 octubre de 1994), Granada, Universidad de Granada (Anónimas y colectivas), 1996, vol. II, págs. 279-290.

Lagos, Ramona, «El incumplimiento de la programación épica en La Araucana», Cuadernos Americanos (México), 1981, CCXXXIII, págs. 157-191.

Lauer, A. Robert, «El baño de Caupolicán en el teatro áureo sobre la conquista de Chile», en Agustín de la Granja y Juan Antonio Martínez Berbel (coords.), op.cit., vol. II, págs. 291-304.
Lee, Mónica Lucía, De la crónica a la escena: Arauco en el teatro del Siglo de Oro, Columbia, University of British Columbia, 1993.

Lerzundi, Patricio, Aranco en el teatro del Siglo de Oro, Valencia, Albatros Hispanófila Ediciones, 1996.

Martínez Chacón, Elena, «Arauco domado, Lope de Vega y Ercilla. Motivación de venganza y panegírico», Revista Chilena de Literatura (Santiago de Chile), 1980-81, núm. 16-17, págs. 229-256.

Mejías López, William, «Principios indigenistas de Pedro de Oña presentes en Arauco domado", Quaderni Ibero-Americani (Torino), Giugno 1993, 73, págs. 77-94.

Navarrete, Rosina D., «'Blasón’ de José Santos Chocano», en [Francisco E.] Porrata y [Jorge A.] Santana, Antología comentada del modernismo..., págs. 530-535.

Nicolopulos, James, «Reading and Responding to the Amorous Episodes of the Araucana in Colonial Perú», en Georgina Sabat de Rivers (ed.), 'Esta, de nuestra América pupila': Estudios de Poesía Colonial, Houston, TX, Society for Reinassance \& Baroque Hispanic Poetry, 1999, págs. 227-247.

Pittarello, Elide, «Aranco domado de Pedro de Oña o la vía erótica de la conquista», Dispositio (Department of Romance Languages, University of Michigan), 1989, vol. XIV, núms. 36-38, págs. 247-270.

Rípodas Ardanaz, Daisy (ed.), Lo indiano en el teatro menor español de los siglos XVI y $X V I I$, transcripción de Inmaculada Lapuista, Madrid, Atlas (Biblioteca de Autores Españoles), 1991.

Rodríguez, Mario, «Un caso de imaginación colonizada: Arauco domado de Pedro de Oña», Acta Literaria (Concepción, Chile), 1981, 6, págs. 79-92.

Romanos, Melchora, «La construcción del personaje de Caupolicán en el teatro del Siglo de Oro», Filología (Buenos Aires), 1993, XXVI, núms. 1-2, págs. 183-204.

Rovira, José Carlos, José Toribio Medina y su fundación literaria y bibliográfica del mundo colonial americano, Santiago de Chile, DIBAM/Centro de Investigaciones Diego Barros Arana, 2002, págs. 9091.

Ruiz Barrionuevo, Carmen, “'En su loco afanar la mente mía’: de Epístolas y poemas a 
Prosas profanas», en Alfonso García Morales (ed.), Rubén Dario. Estudios en el centenario de 'Los raros' y 'Prosas profanas', Salamanca, Secretariado de Publicaciones de la Universidad de Sevilla, 1998, págs. 21-33.

Simerka, Barbara A., "That the rulers should sep without bad dreams': Anti-Epic Discourse in La Numancia and Arauco domado", Cervantes (Bulletin of the Cervantes Society of America), 1998, 18.1, págs. 46-70.
Todorov, Tzvetan, La Conquista de América. El problema del otro, México, Siglo XXI, $2001^{12}$ ( $1^{\mathrm{a}}$ ed. en francés: 1982).

Torre Villar, Ernesto de la, Descubrimiento y conquista de América. Temas para su estudio, México, UNAM, 1992.

Valenzuela Torrealba, Fernando, Visión de la conquista de Chile según la crónica: (Góngora Marmolejo, Mariño de Lobera y González de Nájera), Prólogo de Óscar Espinosa Moraga, Santiago de Chile, Agustinianas, 1986. 